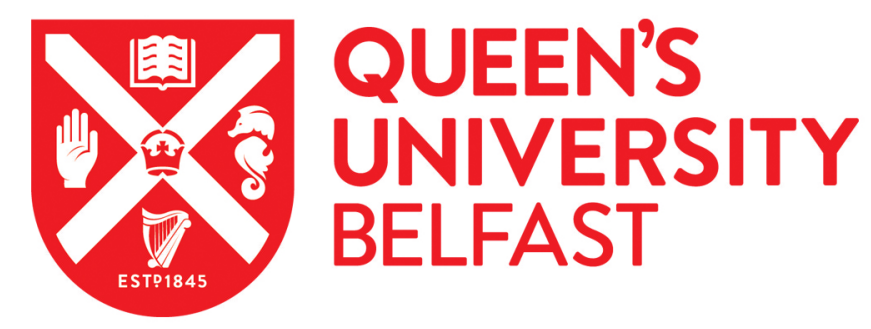

\title{
Quality Assurance Issues in the Teacher-based Assessment of Students with Literacy Difficulties for Examination Access Arrangements
}

McMurray, S., O'Callaghan, P., \& McVeigh, C. (2018). Quality Assurance Issues in the Teacher-based Assessment of Students with Literacy Difficulties for Examination Access Arrangements. Dyslexia, 24(1), 3-16. https://doi.org/10.1002/dys.1576

Published in:

Dyslexia

Document Version:

Peer reviewed version

Queen's University Belfast - Research Portal:

Link to publication record in Queen's University Belfast Research Portal

\section{Publisher rights}

Copyright $\odot 2018$ John Wiley \& Sons, Ltd.This work is made available online in accordance with the publisher's policies. Please refer to any applicable terms of use of the publisher

\section{General rights}

Copyright for the publications made accessible via the Queen's University Belfast Research Portal is retained by the author(s) and / or other copyright owners and it is a condition of accessing these publications that users recognise and abide by the legal requirements associated with these rights.

Take down policy

The Research Portal is Queen's institutional repository that provides access to Queen's research output. Every effort has been made to ensure that content in the Research Portal does not infringe any person's rights, or applicable UK laws. If you discover content in the Research Portal that you believe breaches copyright or violates any law, please contact openaccess@qub.ac.uk. 
Quality assurance issues in the teacher-based assessment of students with literacy difficulties for examination access arrangements

Sharon McMurray (Stranmillis University College)

Paul O'Callaghan (Queen's University)

Claire McVeigh (Stranmillis University College)

\section{ABSTRACT}

This paper considers two major concerns centering on the Joint Council for Qualifications (JCQ) regulations for access arrangement and reasonable adjustments and qualifications for teachers who take on the role of Level 7 access arrangements assessor. Thus, the paper is divided into two parts. First, the JCQ 2017-2018 regulations are critically evaluated highlighting the areas of need for which greater clarity and more extensive detail is required in these regulations. The second part of the paper discusses the findings of research on teacher competence in test administration, scoring, and reporting. Drawing on evidence from the first stage of this research, McMurray, O'Callaghan, and McVeigh highlight the extensive formative process required to build a high-level skill set required for competent assessment involving the use of high level tests and also the specialist knowledge required to analyse and accurately report assessment findings to make recommendations for students with specific literacy difficulties. Recommendations are provided both at policy and practice levels regarding the content of courses and the assessment involving the use of high level tests and also the specialist knowledge required to analyse and accurately report assessment findings to make recommendations for students with specific literacy difficulties. The authors provide recommendations for test publishers, course providers, and assessors.

Under the current Joint Council for Qualifications (JCQ) criteria, there are three 
pathways to qualify as an individual specialist assessor for examination access arrangements. The regulations are clear for the second and third pathways specified under JCQ criterion 7.3; in that, an individual specialist assessor can undertake such assessments if they are either a Health and Care Professions Council (HCPC) registered Psychologist or a practitioner with a specific learning difficulty (SpLD) Assessment Practising Certificate. However, as there are courses available from both private providers and universities in terms of meeting the first pathway of an "access arrangements assessor," there is considerable variation in the content and assessment of the courses on offer. There is currently a "grey area" in the access arrangements assessor pathway specified by JCQ in terms of specifying the exact details of what course content is required and what should be assessed to ensure that teachers have the required Level 7 (Master's level) expertise and skills at both a theoretical and practical level to conduct individual specialist assessments for examination access arrangements. Higher Education Institutions (HEIs) are the bodies who validate courses at Level 7 and are subject to quality assurance procedures that guarantee the standard and quality of learning that students can expect to receive (The Quality Assurance Agency for Higher Education, 2008). The criteria for the JCQ access arrangements assessor pathway; "a postgraduate course at or equivalent to Level 7" (7.3.3) can be read with different interpretations and the need for clarity on some key issues in maintaining quality assurance is the focus for discussion in this paper.

\section{Part One - The issue of quality assurance and levels of detail in JCQ regulations}

The JCQ document places responsibility on Heads of Centre (JCQ regulations 7.2.3) to ensure that the Level 7 access arrangements assessor they appoint is sufficiently qualified and states in 7.3.1 that "JCQ is not able to approve an assessor's qualification(s) and does not maintain a list of appropriate qualifications for assessors" (JCQ, p. 82).

Why then does JCQ inspect qualifications? JCQ specify that evidence of the 
assessor's qualification(s) must be held on file for inspection purposes and be presented to the JCQ Centre Inspector (7.3.4). JCQ produces the regulation concerned but have stated that they do not have responsibility for approving qualifications. The inspection of qualifications is misleading as it implies a role in approval. There is, therefore, conflicting information about the role of JCQ and subsequently a gap in knowledge as to who has fundamental responsibility for the monitoring of quality assurance in ensuring suitably qualified staff for the role of access arrangements assessor. This is a concern for quality assurance within the examination access arrangements system and the reputation of the system as a whole where responsibility for quality assurance is unclear beyond the level of the Head of Centre.

As JCQ is not able to approve qualifications, the JCQ, 2017-2018 document (and any subsequent documents issued) should provide a sufficiently clear explanation of what is required so that the person reading the document can make an informed decision about what constitutes a Level 7 qualification. More detailed guidance is needed so that Heads of Centre can clearly and robustly evaluate the content and methods of assessment used in the various courses on offer from the wide range of providers claiming to qualify teachers as Level 7 access arrangement assessors.

It is proposed that course providers, who are not HEls, should be required to provide information to a centralized quality assurance body on course content and assessment methods and also information on external moderation procedures and annual programme review for the purposes of quality assurance. Without validation by an $\mathrm{HEI}$, students taking a Level 7 equivalent course cannot be certain that the course content and methods of assessment are at Level 7 (Master's level) as there is currently a lack of clarity on course content and methods of assessment within 2017-2018 JCQ criteria. To bring clarity to what is considered an accepted course for qualification as a Level 7 access arrangements assessor, the authors suggest that a centralized quality assurance body should be established with responsibility for ensuring the course content and assessment methods are met at 
Level 7 at both a theoretical and practice-based level. Publication of approved courses, by this body, for this purpose would provide an assurance to teachers and Heads of Centre selecting a course from this quality assured list.

\section{Details of the grey area that exists between level 7 and level 7 equivalent courses}

In relation to content, the JCQ document states that an access arrangements assessor must have successfully completed a postgraduate course at or equivalent to Level 7 that must include training in all of the following (7.3.4):

- "the theoretical basis underlying psychometric tests, such as the concepts of validity and reliability; standard deviations and the normal curve; raw scores, standard scores, quotients, percentiles, and age equivalent scores; the concept of statistically significant discrepancies between scores; standard error of measurement; and confidence intervals;

- the appropriate use of nationally standardised tests for the age group being tested;

- the objective administration of attainment tests that can be administered individually. This must include tests of reading accuracy, reading speed, reading comprehension, and spelling. Appropriate methods of assessing writing skills, including speed, must also be covered;

- the appropriate selection and objective use of tests of cognitive skills, see paragraph 7.5.12, (JCQ, p. 86);

- the ethical administration of testing including the ability to understand the limitation of their own skills and experience, and to define when it is necessary to refer the candidate to an alternative professional" (JCQ, pg. 82).

It is clear from the JCQ regulations stated above that educational testing must be studied and successfully completed at Level 7, which is Master's level.

In 7.3.1, JCQ (p. 82; emphasis added by the authors) have made it clear that the Head of Centre is responsible for 
"checking the qualifications of those assessing candidates (e.g. photocopy of certificate or printout)."

The key word here is "qualifications." The lowest level of postgraduate (Level 7) qualification is a postgraduate certificate, which can only be awarded on the successful completion of 60 CAT points (600 hours of study), 120 CAT points are required for a postgraduate diploma. One hundred and eighty CAT points are required for a Master's degree. It is a concern that the 2017-2018 JCQ regulation 7.3.3 (which relates to an access arrangements assessor who has successfully completed a postgraduate course at or equivalent to Level 7 including at least 100 hours relating to individual specialist assessment) states that:

The reference to at least 100 hours relating to individual specialist assessment would include lecture, seminar and tutorial time, assessment time and time spent completing assignments. Courses which are accredited at AMBDA or APC level would meet this requirement as would post-graduate courses at drequivalent to Level 7 which provide a qualification in access arrangements (JCQ p.82).

If a qualification in access arrangements is to be at Level 7, then it must have at least 600 hours of study (to attain equivalence to 60 CAT points) for an HEI postgraduate certificate. A shorter course would not meet the Master's level 7 requirements for a qualification. AMBDA courses meet this requirement fully and the holder can also be awarded an APC. Other courses that include less than the minimum 600 hours of study should withdraw their claim to Level 7 equivalence, as this is misleading in terms of a comparable level of skill development suggested to be produced in reduced hours of study.

Hours of study are not the sole criterion in what constitutes a Level 7 course. The levels of qualifications specified in both the qualifications framework of the United Kingdom and those of the European Qualifications Framework (The Quality Assurance Agency for Higher Education, 2008, 2014) indicate learning outcomes derived from the increasingly challenging intellectual demands of study. The 5 
authors are aware that there is some misunderstanding in some quarters about what constitutes Master's Level 7, which is incorrectly thought by some to be the length of time engaged in study. Rather, the levels specified in the qualifications frameworks essentially refer to the level of intellectually challenging study resulting in fundamentally different learning outcomes. Theoretical study of psychometrics at Master's Level 7 involves the assessment of the ability to synthesise theory and practice not only in psychometric assessment, but together with the specialist knowledge in the area to be assessed, leading to the ability to make decisions "in complex and unpredictable situations" (The Quality Assurance Agency for Higher Education, 2008, p. 21); to deal with "complex issues both systematically and creatively, and they will show originality in tackling and solving problems" (The Quality Assurance Agency for Higher Education, 2008, p. 22). With regard to teachers assessing for examination access arrangements specialist knowledge of SpLD dyslexia is required to interpret findings. The ability to reformulate and use relevant understanding, assessment methodologies, and professional judgement to address problematic situations that involve many interacting factors is a feature of Master's level (Level 7) study (Qualifications frameworks in the UK, 2009). Critically, however, these skills of interpretation and analysis for the purpose of reporting findings must be underpinned by a valid assessment. Furthermore, under university regulations, Bachelor's Degree courses (Level 6) or/and Foundation Degree courses (Level 5) cannot be combined with Master's courses (Level 7) for the award of a Master's Level 7 qualification. This quality assurance should be applied to all providers to ensure that a Level 5 or 6 course cannot be combined with a level 7 course as this would not constitute a Level 7 qualification under HEI regulations. To claim Level 7 equivalence, qualifications should meet HEI criteria. For example, in the course of this research, it was found that the JCQ (2016-2017) criteria for Level 7 access arrangements assessor qualifications are interpreted by some students, who have undertaken a Level 5 educational testing course, as meaning that educational testing, a core component within this JCQ qualification criteria, when studied and assessed at Level 5 , is sufficient, if a further course relating to 100 hours of individual specialist assessment is also completed. However, the JCQ regulations (7.3.4) make it clear 
that educational testing must be studied and therefore assessed at Level 7. The combination of a Level 5 course in educational testing with a Level 7 course in, for example, analysing the results of assessments, report writing and access arrangements does not meet the JCQ Level 7 criteria for educational testing as outlined in JCQ 7.3.4 as the educational testing element has been studied and assessed at level 5 . The research reported in this paper provides robust evidence that a Level 5 qualification in educational testing is unsatisfactory to meet the JCQ criteria outlined in JCQ 7.3.4. This raises serious concerns about the accuracy and reliability of results obtained by teachers who have not been assessed at Level 7 and found competent in the administration and scoring of all tests they will be using when assessing students for access arrangements. However, the issue goes beyond Level 7 equivalent courses because it is also essential that HEls offer not only Level 7 assessment of understanding at a theoretical level, but also the transfer of this understanding into practice as demonstrated by Level 7 assessment of the practical skills of test administration and scoring that is additional assessment beyond the HEI requirements for a Master's module. The issuing of competence certificates for all of the tests teachers are assessed as competent in using, together with a Level 7 qualification, provides a value-added dimension to any Level 7 qualification and important evidence of competence for the clients they assess and also for JCQ inspectors.

Access arrangements in examinations involve very high stakes and could mean the difference between one grade boundary and a higher grade and subsequently access to a third level course. It must be fair to students who meet the criteria for access arrangements and also to those who do not. An inaccurately administered test, which invalidates the results, is actually harmful. This is because invalid scores from an invalidly administered test creates a false impression of the students' needs and the support that they need resulting in lifelong implications for their educational attainment and job opportunities in the future. It also has implications for students who do not have specific learning difficulties (dyslexia) as a pupil who gets extra time in examinations may achieve a higher grade and obtain a place over a student who has not had extra time in examinations. There needs to be quality assurance to protect the correct application of examination access 
arrangements and reasonable adjustments in order to allow awarding bodies to comply with the duty under the Equality Act (2010) to make reasonable adjustments (Joint Council for Qualifications, 2017-2018, p. 3). They are also needed in order to protect public confidence in the examination access arrangements system and to ensure that students who are assessed for eligibility have received a fair and appropriate standard of assessment.

This research outlined below provides evidence that there are significant gaps in the content of any course that does not engage with a formative process of assessment at Level 7 in the competence of administration of the range of high level tests to be used by each teacher who takes on the role of access arrangements assessor conducting assessments to establish eligibility for examination access arrangements. There must be assessment of the administration of the range of individually administered high level tests a teacher will use in his/her work as an individual specialist assessor for access arrangements in examinations. High level tests are multi-subtest assessments requiring a high level of familiarity with standardised administration procedures in order to be able to correctly identify start and end points for each subtest, administer complex instructions correctly, correctly score verbal responses, provide correct feedback on errors made by the pupil, etc. To draw comparison with other professionals qualified to work in this area, HCPC registered educational psychologists, and psychology assistants who support the work of educational psychologists in Northern Ireland, undergo a rigorous process of evidence-based and theory informed assessment training. Their practical skills in using various complex highlevel tests are rigorously assessed. They do not assess children until they have successfully demonstrated a high level of skill in administering the tests they will be using. Furthermore, the tests that psychology assistants in Northern Ireland can use are restricted to the parts of the tests they have been trained and found competent in using.

The Need for Expertise in the Area in which the Level 7 Access Arrangements Assessor is Assessing 
In 7.1.2, the JCQ regulations state that the assessor must "work only within their area of expertise and in an ethical fashion." If the assessor is assessing literacy difficulties, particularly specific literacy difficulties (dyslexia), it is essential that JCQ ascertains whether the assessor has a Level 7 qualification evidencing expertise in this area. Expertise in specific literacy difficulties (dyslexia) should be taught and assessed in all Level 7 access arrangements assessor qualifications to ensure that judgements surrounding specific literacy difficulties and entitlement to access arrangements are being made in light of up-to-date specialist knowledge.

The need for specialist knowledge in the area of literacy difficulties is a vital component in delivering suitable and appropriate assessments. A theoretical understanding and assessment of competence in the specialist area being assessed at Master's level (Level 7) is essential. Expertise in the area of literacy difficulties is required for the selection of appropriate tests and analysis of results. When drawing together findings from a range of assessments, criticality and professional judgements are needed to synthesise these findings to ensure appropriate recommendations are made. In-depth theoretical knowledge of the difficulties that teachers are assessing is essential in order to make appropriate professional judgements based on specialist knowledge of a child's difficulties that is needed both in planning for an assessment and in making recommendations.

This is important in the case of dyslexia and SpLD, as both the Matthew effect and the varying criteria that can be applied in assessing dyslexic-type difficulties (a point made by Elliott \& Grigorenko, 2014) require high levels of criticality, rigour, and professional judgement in order to be able to make a professional judgement that can be defended. There are potentially serious consequences if this is not done correctly as part of the assessment process. It is not only naive, but also dangerous to underestimate the specialist expertise required to administer tests for the purpose of assessing eligibility for access arrangements in examinations without a solid theoretical grounding at Level 7 in a specialism such as specific literacy difficulties (dyslexia). Assessors are placed in a very vulnerable position, not only from potentially inaccurate test administration but also from a lack of specialist knowledge in the area of literacy difficulties. If an assessor has not 
completed a course that addresses difficulties in literacy development, such as working memory difficulties, motor processing difficulties, spelling difficulties, rate of reading, and speed of processing, they will not have had their knowledge and understanding of these difficulties assessed and their ability to select appropriate tests and make appropriate recommendations may be contested.

For example, JCQ state that

The vast majority of candidates awarded 25\% extra time will have an assessment of speed of processing or working showing at least one standardised score of 84 or less.(JCQ, p. 24)

$J C Q$ list these difficulties in speed of processing or working as being one or more of the following:

- speed of reading;

- speed of reading comprehension;

- speed of writing; or

- cognitive processing measures that have a substantial and long term adverse effect on speed of working (JCQ, p. 22)

Ferrier, Horne, and Singleton (2013) contest the use of speed of free writing to justify the provision of examination access arrangements or accommodations concluding that vulnerability to teacher effects and other factors makes free writing an unreliable method of measuring writing speed. Ferrier et al. (2013) claim that up to $70 \%$ of children at age 11 could be eligible for extra time under this criterion. Montgomery (2007) has also highlighted the importance of teaching in establishing good handwriting skills and Montgomery reports research by Alston (1993) that found that $20 \%$ of pupils in secondary schools were not writing well enough for the demands of the secondary curriculum.

It seems reasonable to suggest that an assessor with insufficient specialist knowledge might recommend access arrangements for a student with a score of 84 or less in speed of writing, who has always been slow in getting work finished but not as a result of a disability as intended in the Equality Act (2010). JCQ stress that "the SENCo must present for inspection purposes a substantial and 
comprehensive body of evidence" (JCQ, p. 24), and therefore, a score of 84 on its own would be insufficient evidence. There is, however, a risk that without appropriate theoretical expertise on the part of the access arrangements assessor, the scores could be inappropriately selected and recorded on the Form 8, for example, on the basis of illegible handwriting resulting from poor attention to handwriting and presentation skills as opposed to evidence of an SpLD. Indeed, an assessment by an occupational therapist would be required if the assessor considered the difficulties to be the result of a developmental co-ordination disorder.

Furthermore, a standardised score of 84 in itself is problematic as this score could not be reliably deemed to be more than one standard deviation from the mean. Confidence intervals associated with a particular test have to be taken into account and were they to be wide it is highly probable that the students' "true" score would actually fall in the average range. This could result in a student getting access arrangements who is not eligible under the Equality Act (2010). The converse scenario could occur where a student with specific learning difficulties (dyslexia) is inaccurately assessed by a post-primary school specialist assessor who has not had rigorous training and assessment in all the tests they administer. As a result, the pupil gets no additional support in school and is deemed ineligible for access arrangements. If the parents were to obtain an independent assessment and this assessment provided evidence of the child's eligibility for additional support in school and eligibility for access arrangements, then a legal case may scrutinise the qualifications of both assessors to ascertain whose assessment is valid. If a level 7 access arrangements assessor was found to be inadequately qualified and results from testing therefore to be invalid, then the assessments conducted by the access arrangements assessor with other students could be called into question and would have to be investigated. This could have legal ramifications if these students were found to be entitled to support that they did not receive, potentially impacting on grades and opportunities.

The suggestion within the JCQ regulations that at "least one standardised score of 
84 or less" (JCQ, p. 24) could be taken at face value and one test with a standardized score of 84 could be interpreted as providing sufficient evidence on which to process and award examination access arrangements using the JCQ online system unless JCQ (2017-2018: 24) ensure that they inspect "the substantial and comprehensive body of evidence" for every case and verify that the evidence supports the claim for access arrangements.

The issue of needing to consider confidence intervals when interpreting scores, building a picture of a pupil's needs, and subsequently making decisions on entitlement to examination access arrangements should always encompass a range of assessment data. The Equality Act (2010) definition of disability is usually considered cumulatively in terms of identifying a physical or mental impairment; looking into adverse effects and assessing which are substantial; considering if substantial adverse effects are long term; and judging the impact of long term adverse effects on normal day to day activities (JCQ, p. 4). This multistep process of compliance requires building a picture of a pupil's needs. However, JCQ have not, until now, inspected the record of evidence held on the school premises for each child who obtains access arrangements arising from the online application. The change in the 2017-2018 document (JCQ, p. 24) stating that the SENCo must present this evidence for inspection purposes is welcome, but is the inspector qualified to identify any unsatisfactory evidence? It is essential that JCQ ensure that there is no risk that the individual specialist assessment process, in some cases, could be a reductionist process with decision-making based on one test score at 84 or below because the assessor is insufficiently well qualified to analyse assessment findings correctly. This is very different to the process of building a picture of a child's needs and making a professional judgement that is grounded in specialist knowledge of theory and practice and knowledge of the latest evidence in their area of expertise.

This is clearly the intention of the JCQ regulations as they stipulate in 7.1.2 that the assessor must "work only within their area of expertise" to minimise any risk that access arrangements assessors can come under legal challenge if the course they undertake to meet the JCQ regulations does not provide the level of training 
required to ensure they are adequately skilled. The provision of a level playing field for all pupils including those with, and without, disabilities has already been queried in England (Information Commissioner's Office (ICO), 2015; Ofqual, 2012). The ICO (2015) freedom of information case highlights the potential risk of litigation from parents of children who do not have a disability if there are students receiving access arrangements who are found not to meet the criteria but have obtained access arrangements due to an invalid assessment. Concerns are already being raised in England regarding the validity of data used to recommend examination access arrangements (Ofqual, 2012; ICO, 2015). The research reported in this paper is ongoing, and the growing body of evidence would indicate that the examination system is undermined by unsatisfactory quality assurance procedures in relation to qualifications for individual specialist assessors. Based on the evidence presented here, there is concern that test results obtained, by the inadequately qualified assessors who do not have an APC or are not an HCPC registered psychologist, could be invalid. To safeguard the system, it is essential that teachers who undertake the role of assessor for examination access arrangements have had their test administration and scoring, for each of the tests they are using, assessed and have been found competent in the administration and scoring of each test.

\section{Part Two Research}

This paper discusses the research evidence from the first 27 participants in an ongoing study, which focuses on the theoretical knowledge and practical skills necessary for the role of access arrangements assessor for GCSE and A Level examinations. This first phase began in 2015 and 2016, with new participants entering the study in 2017 and 2018.

Twenty-two teachers (Cohort 1) entered the study in Semester 2 (2015) in the academic year 2014-2015. Nine of these teachers held a previous qualification in educational testing on entry. Eighteen of these teachers (nine who had no previous qualification in educational testing and nine who had) submitted at three 
time points; Time 1, June 2015; Time 2, October 2015; and Time 3, June 2016. Of the original 22 teachers, two dropped out after Time 1 because they found the administration of high level tests too difficult and did not want to proceed, and two teachers deferred and entered the study again with the third cohort of teachers (September 2016, this third cohort $n=19$ entered the study at time of writing and are therefore not reported here).

A further five teachers (Cohort 2) entered the study in Semester 2 (2016), in the academic year 2015-2016, and submitted their Time 1 assessment in June 2016 with the first cohort of teachers who were submitting their Time 3 assessment. This first assessment by Cohort 2 is reported in these results. All of the teachers in this study were enrolled on a 30 CAT point Master's module on psychometrics and report writing, which also included the assessment of each student's practical administration, scoring, and reporting of findings from three high level tests at Time 1, with detailed formative feedback on their test administration, scoring, and reporting. The module involved blended learning with online presentations and readings to develop theoretical understanding, online presentations by an educational psychologist demonstrating the administration of tests 1-3 listed in Table 1, and practical activities and online tests to assess understanding of what was covered in each of the 10 sessions on the course as well as the submission of academic assignments for the award of the Master's module. There were also face-to-face sessions to develop theoretical and practical skills working together in a group environment. Cohort 1 then moved to a 60 CAT point module, undertaking case study research in the area of specific literacy difficulties (dyslexia), and their practical skills in test administration, scoring, and reporting were assessed at Time 2 (October/November 2015) and Time 3 (June 2016). Detailed formative feedback was also provided at Times 2 and 3. Four teachers opted to administer the WIAT-IIUK-T (Wechsler, 2006) with no training or access to training videos.

They chose the WIAT-II ${ }^{\mathrm{UK}}$-T as they felt the Diagnostic Reading Analysis test (Crumpler \& McCarty, 2004) was not an appropriate test for the pupils they were assessing, given the age of the pupils. All four of these teachers already had a qualification in educational testing. Their expectation was that, as they already had 
a qualification in educational testing and had been involved in testing in their school prior to participating in this programme, they would be able to achieve competence without specific training on the WIAT-II ${ }^{\mathrm{UK}}$-T. All four failed the test administration on first submission, one passed on second submission, and one passed on the third attempt. Detailed formative feedback was given after each submission. The fourth teacher did not want to proceed to a fourth submission. All four teachers emphasised how difficult it was to administer the test correctly without specific training in the test, stating that the formative feedback provided insight they were unable to gain from independent study of the manual or their own self-evaluation of assessment practice.

\section{Pass /Fail Criteria}

\begin{tabular}{|c|c|c|c|c|c|c|c|}
\hline Test & Name of Test & $\begin{array}{l}\text { Time } 1 \\
\text { Total number } \\
\text { Cohort } 1 \text { and } \\
\text { cohort } 2 \\
\text { students }\end{array}$ & $\begin{array}{l}\text { Time 1 } \\
\text { Pass Rate }\end{array}$ & $\begin{array}{l}\text { Time } 3 \\
\text { Total number } \\
\text { Cohort } 1 \\
\text { students only }\end{array}$ & $\begin{array}{l}\text { Time } 3 \\
\text { Pass Rate }\end{array}$ & $\begin{array}{l}\text { Resubmission } \\
\text { by teachers } \\
\text { who failed at } \\
\text { Time } 3\end{array}$ & $\begin{array}{l}\text { Time } 4 \\
\text { Pass Rate }\end{array}$ \\
\hline 1 & $\begin{array}{l}\text { Wide Range } \\
\text { Intelligence } \\
\text { Test (WRIT) }\end{array}$ & $\begin{array}{l}n=27 \\
\text { ( } n=22 \text { cohort } 1 \\
n=5 \text { cohort } 2 \text { ) }\end{array}$ & $\begin{array}{l}8 \% \\
n=2\end{array}$ & $n=18$ & $\begin{array}{l}83 \% \\
n=15 \\
\text { ( } 3 \text { fails } 2 \text { candidates } \\
\text { advised to withdraw) }\end{array}$ & $n=1$ & $\begin{array}{l}100 \% \\
n=1\end{array}$ \\
\hline 2 & $\begin{array}{l}\text { Dyslexia } \\
\text { Portfolio (DP) }\end{array}$ & $\begin{array}{l}n=27 \\
\text { ( } n=22 \text { cohort } 1 \\
n=5 \text { cohort } 2 \text { ) }\end{array}$ & $\begin{array}{l}26 \% \\
n=7\end{array}$ & $n=18$ & $\begin{array}{l}83 \% \\
n=15 \\
\text { ( } 3 \text { fails } 2 \text { candidates } \\
\text { advised to withdraw) }\end{array}$ & $\mathrm{n}=1$ & $\begin{array}{l}100 \% \\
n=1\end{array}$ \\
\hline 3 & $\begin{array}{l}\text { Diagnostic } \\
\text { Reading } \\
\text { Analysis }\end{array}$ & $\begin{array}{l}n=23 \\
\text { ( } n=18 \text { cohort } 1 \\
n=5 \text { cohort } 2 \text { ) }\end{array}$ & $\begin{array}{l}47 \% \\
n=11\end{array}$ & $n=14$ & $\begin{array}{l}71 \% \\
n=10 \\
\text { ( } 4 \text { fails } 2 \text { candidates } \\
\text { advised to withdraw) }\end{array}$ & $n=2$ & $\begin{array}{l}100 \% \\
n=2\end{array}$ \\
\hline 4 & $\begin{array}{l}\text { Wechsler } \\
\text { Individual } \\
\text { Achievement } \\
\text { Test WIAT- } \\
\text { "IUK-T }\end{array}$ & $\begin{array}{l}\mathrm{n}=4 \text { cohort } 1 \\
\text { students }\end{array}$ & $\begin{array}{l}0 \% \\
n=0\end{array}$ & $\begin{array}{l}n=3 \\
\text { ( } n=1 \text { passed at } \\
\text { time } 2 \text { ) }\end{array}$ & $\begin{array}{l}\mathrm{n}=2=66 \% \\
\text { ( } \mathrm{n}=1 \text { failed at TIME } 3 \\
\text { and opted not to } \\
\text { submit for a } 4^{\text {th }} \text { time) }\end{array}$ & $n-0$ & \\
\hline
\end{tabular}

TIME 1 for cohort 1 was June 2015 TIME 3 for cohort 1 was June 2016

In analysing each assessor's test administration, deviations from standardised 
administration (as outlined in the manual) were coded into two main categories. Firstly, there were minor errors, which although involving incorrect administration did not affect the total score obtained by the pupil in a subtest. Minor errors include omitting to read a line of additional instructions supplied in the manual (when it was apparent that the pupil had already understood the task anyway), failing to start the timer at exactly the correct time (but where it was obvious that the pupil completed the task within the time allowed for the subtest item), or failing to read instructions verbatim (when it was apparent the paraphrased instructions conveyed the key points required). In this case, feedback was provided to correct minor errors, but no assessor failed the test as a result of a minor error.

The second category of errors are administration errors that resulted in an invalid score being recorded on the test. This could have occurred when an assessor failed to credit previously un-administered items that were deemed to be answered correctly in a subtest involving specific age-related start points, incorrectly reading a scoring table when computing a standardised score, ending a subtest prematurely before the discontinuation rule was reached, failing to establish a basal set, or arithmetic errors resulting in the incorrect standard score, percentile rank, or reading age being reported, or poor adherence to standardised wording where key points were not conveyed and the validity of the item was compromised. After formative feedback was given and any major errors addressed, the assessor administered and scored the test again to demonstrate that competency had been achieved.

One of the greatest challenges faced by teachers in administering tests was remembering not to give positive feedback for correct answers and refraining from helping pupils who were struggling to complete subtest items. For many teachers, praising children and scaffolding learning was so ingrained in their practice as teachers that it seemed "unnatural" not to praise correct responses or assist pupils who were struggling to read or comprehend text. However, over time it became evident that certain individuals had a particular aptitude for 
administering a test with a very high degree of accuracy, they were highly accurate in replicating standardised instructions during assessments and developed a high level of competence in scoring and accurately calculating standard scores, percentile ranks, and reading scores from the raw scores obtained. At the same time, there was also a small cohort of assessors who, despite extensive formative input, continued to struggle to accurately administer high-level tests and tended to make multiple errors in any test they administered, despite feedback.

This led the research team to hypothesize that (a) the skill set required to accurately administer a high-level test is quite different from the skill set required to teach and (b) that the skills required for high-level test administration involve an interplay between skills that can be learned as well as inherent information processing skills that are less amenable to teaching than we had first thought. Thus, not every teacher can develop the specialist high-level skill needed to become a competent individual specialist assessor at Level 7, when using highlevel individually administered tests, no matter how much input they receive. This was found to be the case even though participants had passed all theoretical assessments demonstrating understanding at a theoretical level. It is vital that more stringent assessment of assessors' practical skills (demonstrating the application of theory to practice) be undertaken to ensure that only people with both the theoretical knowledge and the ability to accurately administer high-level tests are permitted to do so. This is a concern because some test publishers provide access to high-level tests if teachers have a Master's qualification in, for example, SEN, but do not require evidence of competence in the practical administration, scoring, and interpretation of the particular test the teacher is ordering.

At Time 3, 18 of the original 22 teachers in Cohort 1 remained in the study. After submission of the filmed assessment at Time 3, 17 of the remaining 18 teachers attended a final seminar and completed a questionnaire. After the Time 3 test administrations were assessed, 2 of the 18 teachers were advised not to submit 17 
for a fourth time as they failed all three tests on three occasions and their errors were across all areas of administration and scoring. Three teachers were permitted to submit one or two of the tests for a fourth time; one teacher had failed two tests at Time 3 and two teachers failed one test.

\section{Teacher questionnaires}

The teachers were asked what they found helpful in developing their expertise in individual specialist assessment. Eleven of the 17 teachers said that the 24/7 availability of the online module presentations and resources was important because they could revisit aspects of the course again and study at a time convenient to them. Ten found interacting with fellow students at face-to-face sessions helpful. Two found dedicated time they were given in school to practise assessments helpful. Six found tutor support in the face-to-face sessions helpful. All 17 teachers found the online videos of test administration helpful and all 17 found the formative feedback of their administration of the tests critical in developing their competence.

Only 2 of the 17 teachers were provided with dedicated time in school to practise the administration of the tests, all of the other teachers practised test administration with family and friends at home. All of the teachers considered the formative feedback they received from the educational psychologist to be essential in developing their skills. Having completed the course and gone through the process, all of the teachers recognized the importance of regular practice to maintain their skills. Moving forward, having completed the course, 14 of the 17 teachers considered training and assessment in the administration of any other tests they might use in the future and the issuing of a competence certificate to be essential. Educational psychologists are administering tests daily, and therefore, maintenance of their skills is ensured. All of the teachers recognized the drawback in not being in a position to administer tests regularly and recognized the importance of maintenance of skills to ensure correct administration and scoring, and thus valid results. 
The key findings from this research are

1. Competence in the administration of one test does not ensure competence in the administration of another test.

2. The skill set required for psychometric assessment is very different from the skill set for teaching.

3. There was no difference in the performance of teachers who already had a qualification in educational testing on the administration of the tests in this study as compared to teachers without previous qualifications. This provides evidence that teachers require a formative process of continuing professional development in each test to achieve competence. This finding raises concerns about existing standards currently in place to adequately distinguish individual assessor's competences in administering complex psychometric tests at Level seven.

4. Assessors must conduct individual specialist assessment regularly to maintain their skills. Once an assessor has been found competent in the administration of specific named tests, regular and ongoing test administration of those named psychometric tests is essential to the maintenance of a high level of skill set in test administration and scoring. Practice should include a "back-tobasics" approach employed at the outset of each period of assessment in order to refresh and maintain good practice in strict accordance with specifications of the test manual.

5. A process of extensive training, assessment and formative feedback is needed at a practical level for each psychometric test the assessors are trained in the use of.

6. Assessment of competence must be based on the examination of footage of the administration of the test in full and not on a sample of their administration, to ensure competence in the entire test. There must be assessment of competence in the selection, administration, scoring, analysis, and reporting of the findings from the range of high level tests (Level 7) that a teacher selects to use to assess young people with literacy difficulties for 
examination access arrangements.

7. A substantive element of any course should address SpLDs, particularly specific literacy difficulties (dyslexia) and associated issues in cognitive processing to ensure that teachers can work within this area of specialism and comply with JCQ regulation 7.1.2.

8. Research findings indicate that regular practice of test administration is essential to the maintenance of an assessor's high-level skill set and subsequently the production of reliable and accurate reports.

9. Within any qualification for individual specialist assessors, there are three main areas that should be taught and assessed at Level 7.

- educational testing at both a theoretical and practical level;

- literacy difficulties with a focus on specific literacy difficulties (dyslexia); - analysis and synthesis of a wide range of assessment findings, report writing, and issues in examination access arrangements.

\section{Discussion and Recommendations}

To protect assessors from legal action and to ensure the examination system is fair to all pupils, this research highlights the need to establish quality assured criteria that course providers should adhere to with regard to qualifications for Level 7 access arrangements assessors.

The authors propose that additional detail should be included in the JCQ course content criteria to help teachers to make an informed decision when choosing a course to qualify as a Level 7 access arrangements assessor. This detail would also help Heads of Centre to make an informed decision as to whether the specialist assessor conducting examination access arrangements is qualified to do so.

Arising from these research findings, it is recommended that schools cluster and teachers who work as access arrangements assessors have the opportunity to assess in a number of schools at regular intervals throughout the school year in order to maintain their specialist skill set. 
The following evidence-based recommendations on course content are presented here to ensure that teachers working in this area are operating at the high level of expertise and skill required to produce reliable and valid findings in this complex and litigious area of SEN in literacy. These are specified in turn.

\section{Recommendations for course providers}

Qualifications for access arrangements assessors should assess each of the following three areas at Master's Level 7. It is not satisfactory that any of the criteria listed below is assessed at a level below Level 7.

1. Educational Testing (minimum 300 hours of study)

- The theoretical basis underlying psychometric tests, such as the concepts of validity and reliability; standard deviations and the normal curve; raw scores, standard scores, quotients, percentiles, and age equivalent scores; the concept of statistically significant discrepancies between scores; standard error of measurement and confidence intervals; and the application of this knowledge in the selection of suitable tests to assess the needs of the student and the correct administration, scoring, and analysis of results;

- the appropriate use of a range of nationally standardised, individually administered high-level tests for the age group being tested. High-level tests are multi-subtest assessments requiring a high level of familiarity with standardised administration procedures in order to be able to correctly identify start and end points for each subtest, administer complex instructions correctly, correctly score verbal responses, provide correct feedback on errors made by the pupil, etc. There should be assessment of the administration and scoring of the required range of high-level tests to be used by the assessor on three occasions over the duration of the course, this should ensure the assessment of the administration of the entire test for each test and include formative feedback on each occasion. The 
administration of one standardised test from each of the categories below (ability, attainment, and cognitive processing) should be assessed at three time points over the duration of the course with a different candidate being assessed on at least two of these time points or all three time points if using the same candidate would result in practice effects.

A. ABILITY - the objective administration of a high-level, individually administered standardised test of ability; competence in the individual assessment of verbal and non-verbal ability demonstrates Level 7 knowledge, understanding, and skills.

B. ATTAINMENT-the objective administration of high level standardised attainment tests that can be administered individually. This must include tests of reading accuracy, reading speed, reading comprehension, and spelling.

c. COGNITIVE PROCESSING - the appropriate selection and objective use of tests of cognitive processing, for example, investigations of short-term/ working memory, phonological processing (e.g., phonological awareness, phonological memory, and/or rapid naming), or other measures as determined appropriate for the candidate by an assessor;

- a standardised assessment of speed of handwriting and interpretation of results to ascertain whether difficulties may be arising from a motor processing difficulty (requiring referral to an OT for assessment) or from poor handwriting due to limited formal teaching of handwriting skills;

2. Literacy difficulties with a focus on specific literacy difficulties (dyslexia; minimum 200 hours of study)

- knowledge and understanding of SpLDs, particularly specific literacy difficulties (dyslexia);

- knowledge and understanding of associated issues in cognitive processing;

- knowledge and understanding of affective issues;

- knowledge and understanding intervention for students with dyslexia.

3. Analysis and synthesis of a wide range of assessment findings, report writing 
and issues in examination access arrangements (minimum 100 hours of study)

- analysis and synthesis of assessment findings from the required range of high level tests and the wider assessment framework;

- written reports conveying the assessment findings and making appropriate recommendations;

- issues in examination access arrangements.

In addition to the Master's level (Level 7) requirements, students must demonstrate a working knowledge of regulations for assessing for examination access arrangements, knowledge of the Equality Act (2010), and the ethical administration of testing including the ability to understand the limitation of their own skills and experience, and to define when it is necessary to refer the candidate to an alternative professional, as specified by current JCQ criteria.

In addition to the Level 7 academic qualification issued by the HEl or course provider, competence certificates should be issued for each named test that the test user has been found competent in using. It would be up to each course provider to decide the additional cost to students for value-added certificates of test competence.

\section{Recommendations for test publishers.}

Test publishers should permit the sale of individually administered high-level multicomponent tests to school principals who should be required to ensure that teachers, who are training in the use of the test, have access to the test while they are being trained in its use.

Test publishers should require the school principal to ensure that only teachers who successfully achieve a competence certificate for any given individually administered multicomponent psychometric test have access to it and permission to use it with students. In the case of teachers who are not employed in a school, 
it is suggested that test publishers or the course provider may consider supplying the tests retaining, for example, a non-refundable deposit for the period of the course, with an agreement that the student purchase the test if they pass the course or return it if they are unsuccessful.

\section{Recommendations for schools}

School principals should ensure that individually administered high-level multicomponent psychometric tests are kept under restricted, lock and key conditions and are only used by teachers who have a competence certificate for each of the tests they use.

School principals should allow teachers, who are engaged in an appropriate programme of postgraduate study, to access the psychometric tests held by the school as part of their training during the course of their enrolment on their programme of study.

\section{Recommendations for teachers who assess students}

Suitably qualified teachers who conduct access arrangements assessments should be required to provide evidence of their assessment qualifications to all clients providing details of their Master's Level 7 qualification(s) and also the competence certificate for each of the tests they use.

During the course of postgraduate study towards a suitable qualification, it is recommended that the teacher makes clear to the principal and any pupils and parents/guardians that they work with to produce training assessments that the training assessments and their results are for training purposes. Prior informed consent to conduct such training assessments should be sought on this basis. 


\section{Conclusions}

The increased training for teachers who take on the role of Level 7 access arrangements assessor in practical skills in test administration, the development of specialist knowledge of specific literacy difficulties and in Level 7 study would be advantageous to the Level 7 access arrangements assessor, SENCo, and Head of Centre alike in terms of ensuring that accountabilities can be correctly met and a fair and equitable assessment upheld on the basis of the assessor having a sufficient standard and range of knowledge, understanding, and skills in order to comply with the requirements of their role. In turn, this would increase the confidence of the general public.

There is an urgent need to establish a centralised verified list of approved Level 7 access arrangements courses that meet the criteria specified here.

Based on the findings discussed in this paper, it is the view of these authors that the current JCQ Level 7 qualification criteria for eligibility to assess students is unsatisfactory, leading to concerns over fairness and equality of access as a result. The authors call for a centralised quality assurance body to be established in order to bring greater clarity as to acceptable qualification standards in this area for the benefit of Heads of Centres, assessors working in this area, and the general public.

ORCHID

Sharon McMurray http://orcid.org/0000-0002-2293-1928

Contact: s.mcmurray@stran.ac.uk

McMurray, S., O'Callaghan, P \& McVeigh, C. (2018) Quality assurance issues in the teacher-based assessment of students with literacy difficulties for examination access arrangements. Dyslexia. 24:3-16., http://doi.org/10.1002/dys.1576. Accepted 14 November 2017 


\section{References}

Alston, J. (1993). Assessing and Promoting Writing Skills. Stafford: Nasen.

Crumpler, M., \& McCarty, C. (2004). Diagnostic Reading Analysis. UK: Hodder.

Elliott, J. G., \& Grigorenko, E. L. (2014). The dyslexia debate. New York: Cambridge University Press.

Ferrier, J., Horne, J., \& Singleton, S. (2013). Factors affecting speed of free writing. Journal of Research in Special Educational Needs, 13(1), 66-78.

Her Majesty's Stationery Office (2010). The Equality Act. London: Stationery Office.

Information Commissioner's Office (2015). Freedom of Information Act 2000 (FOIA) Decision notice Reference: FS50544524.UK: Information Commissioner's Office.

Joint Council for Qualifications (2016). Adjustments for candidates with disabilities and learning difficulties Access Arrangements and Reasonable Adjustments. UK: Joint Council for Qualifications.

Joint Council for Qualifications (2017). Adjustments for candidates with disabilities and learning difficulties Access Arrangements and Reasonable Adjustments. UK: Joint Council for Qualifications.

Montgomery, D. (2007). Spelling, Handwriting and Dyslexia. Abingdon, Oxon: Routledge.

Ofqual (2012). Ofqual's position on extra time for candidates taking timed examinations. UK: Ofqual.

Qualifications Frameworks in the UK (2009). Referencing the qualifications framework of the United Kingdom to the European Qualifications Framework. 
UK: Qualifications Frameworks in the UK.

The Quality Assurance Agency for Higher Education (2008). The framework for higher education qualifications in England, Wales and Northern Ireland August 2008. Gloucester: QAA.

The Quality Assurance Agency for Higher Education (2014). Qualifications can cross boundaries - a guide to comparing qualifications in the UK and Ireland. UK and Ireland: QAA.

Wechsler, D. (2006). Wechsler Individual Achievement Test Second UK Edition (WIAT-IIUK-T). UK: Pearson. 